\title{
Coal fires a major source of greenhouse gases- a forgotten problem.
}

\author{
Hartwig Gielisch", Christian Kropp \\ DMT GmbH \& Co. KG, Germany, Am Technologiepark 1, 45307 Essen, Germany
}

\begin{abstract}
Coal fires seriously pollute the environment in several states of the world. Today most coal fires are manmade and emerge from illegal or unprofessional mining activities. The most disastrous coal fires of the world currently occur in China and India. In China the program "Great Leap Forward" in the beginning of the 60ties together with inefficient small scale mining are the main reasons of the 750 coal fires in China, where almost 200 Mt of excellent, near surface coal were burned in uncontrolled coal fires. In India disregard of standards with regards to coal fire prevention is the reason of the burning coal fields. The Jharia Coalfield in Jharkhand started burning in 1916 and burns this year for 100 years. General data on the volume of coal, which burns in Indian coal mines are not available. In general, coal fires start as result of unprofessional or illegal mining activities in open pits and uncontrolled, inactive coal mines by self-combustion of coal. Self-combustion is mainly controlled by the grain size of the coals, in other words the smaller the grain size the higher the risk of oxidation and subsequent temperature build-up. Many coal fires burn underground with variable supply of oxygen. Hence, the coal does not burn completely like in power plants, but it smolders in the underground. Emissions from these smoldering fires and an incomplete combustion of the coal create dust and greenhouse gases such as $\mathrm{NO}_{\mathrm{x}} \mathrm{CO}_{2}, \mathrm{CO}_{2 \text { equi., }} \mathrm{CO}$ and $\mathrm{CH}_{4}$. These emissions pollute the soil, groundwater and the atmosphere. Coal fire experts discuss since years the percentage and the cumulative influence of coal fires on global warming and climate change. Until now the percentage of greenhouse gases resulting from coal fires is unknown. The quantification of this percentage is a future duty of firefighting companies and organizations.
\end{abstract}

Keywords: Chiral auxiliaries, enantiomericaly pure, pheromones.

\section{Introduction}

Coal fires occur everywhere in the world in all climate zones, in arid to humid climate, in tropic climates up to the Polar Regions. These fires pollute the environment by wasting the groundwater with all kinds of organic compounds like benzene, benzopyrene, dicyclopentadiene, sulphuric acid etc. In addition they cause geo-hazards such as sink holes and landslides. The pollution caused by these fires affects air, water and land. Smoke from these fires contains poisonous gases, such as oxides and dioxides of carbon, nitrogen and sulphur, which are the causes of severe lung and skin diseases. The largest fires are burning in the coal belt of north China, in the Jharia region in East India and in the USA. Also coal fires occur in Germany, Poland, Ukraine, Kosovo, Indonesia, Canada, Southern Africa (South Africa, Botswana etc.), in the Russian Federation, New Zealand and in Venezuela.

The main reason of the spontaneous self-ignition of coal is unscientific or illegal mining. Due to the character of the coal the fires start in areas were coal comes in contact with oxygen. These coal fires are caused anthropogenic and emerge from crude mining activities. There are a lot of coal fires in active mines, but the main dangers are uncontrolled fires in inactive or illegal mines. Following the results of a Sino-German Research project the coal in open pit and unprotected, inactive underground mines starts to burn on account of self-combustion.
The self-combustion results only from the grain size of the coal: with an increasing danger of oxidation the smaller the grain size. So uncontrolled, inactive or illegal coal mines are the reason of the coal fires. The main areas where the coal fires are a natural hazard of global importance are China and India.

In China, nearly 750 coal areas and mining fields are on fire. Around $20 \mathrm{Mt}$ of coal are burning every year and about $200 \mathrm{Mt}$ are wasted by the fires [1]. The main reason of the enormous problem is the structure of the Chinese mining industry. In the communist program "Great Leap Forward" in the beginning of the 60ties the Chinese government intended to establish local coal mines run by the local farmers. The result of these politics was the occurrence an inefficient small scale mining in "mini mines" run by worker without any education or experience. These "Great Leap Forward" effects the Chinese coal industry until now. 2004 China produced all in all 1.600 Mt of coal. Around $400 \mathrm{Mt}$ of coal of this production were mined in major state owned mines. 1.200 Mt of coal was mined in village mines and small private mines with up to 20 miners. In such mines without mine safety engineer, mine surveyor or geologist coal fires start.

In India disregard of standards with regards to coal fire prevention is the reason of the burning coal fields. The Jharia Coalfield in Jharkhand, which have the best coking coals in India, started burning in 1916 and burns last year for 100 years (Figure 1). 


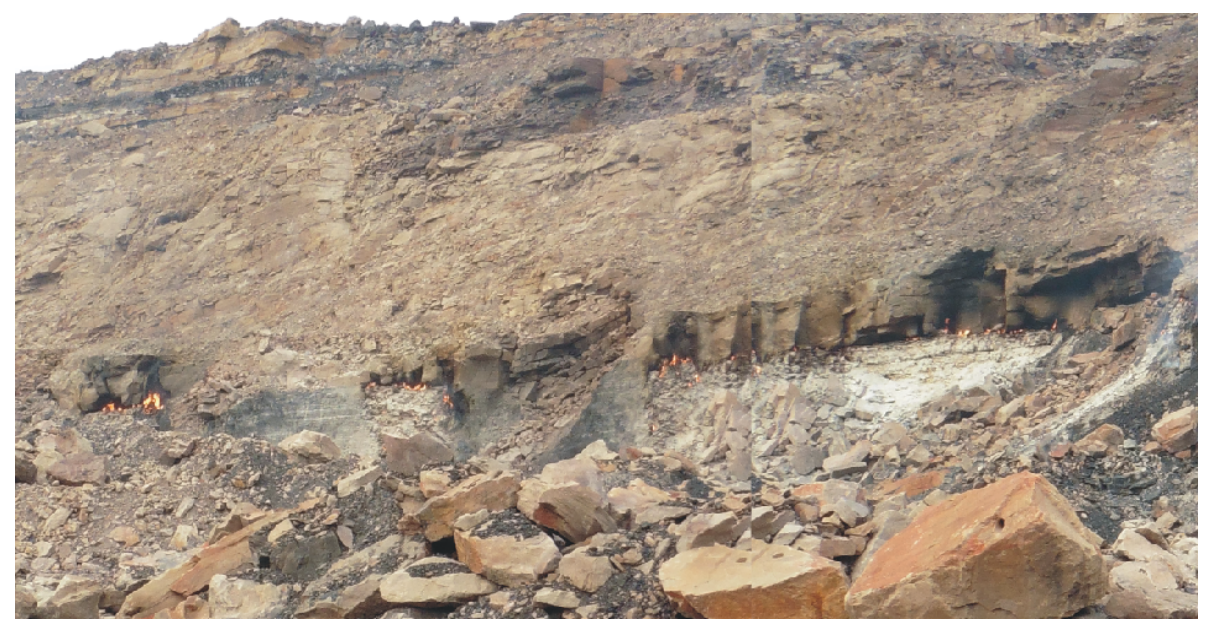

Figure 1. Burning coal fire in the Jharia Coal Field.

"...According to BCCL, mining in the Jharia Coalfield (JCF) started in 1894 and the first fire was reported in 1916 at Bhowrah Colliery.... ....It needs to be mentioned here that JCF is the only source of prime coking coal in the country. After nationalization of coal mines in 1972-73, investigations carried out revealed 70 fires covering an area of 17.32 square $\mathrm{km}$ of BCCL. Subsequently, seven more fires were identified, taking the total number to $77 \ldots$. "

(Jayanta Gupta | TNN | Times of India; Feb 10, 2016)

These coal fires burn in active mining fields, under cities and villages and following newer information nearly 90.000 houses are affected by the fires. In India the main problem is the illegal or unscientific mining. This rat hole mining destroys the coal field and lead to coal fires. Also a big problem is that since 100 years nobody seems to be responsible for these fires. Up to today general data on the volume of coal, which burns in Indian coal mines or official statements to the amount of coal destroyed by coal fires, are not available.

\section{Definition of Coal Fires}

A coal fire is a fire started by spontaneous self-ignition of a natural coal seam or of residual coal in old or still active underground and open pit mines. The loosening of the coal as a result of mining activities or tectonic motions enables oxygen to interact with a larger coal surface; this leads to increased oxidation of the coal and self-ignition. In a common sense, the phenomenon of self-ignition of coal means the onset of exothermic chemical reactions and a subsequent temperature rise within the combustible material, without the action of an additional ignition source. Generally, self-ignition is supposed to occur when the thermal equilibrium between the two counter-acting effects of heat release due to the oxidation reaction and heat loss due to the heat transfer to the ambient is disturbed. In case that the rate of heat production exceeds the heat loss, a temperature rise within the material will consequently take place including a further acceleration of the reaction. This positive feed-back loop ends up in self-ignition, finally [2]. Every coal has the tendency to spontaneous combustion. Anthracites sampled in NW China, which do not combust in the laboratory in Germany under an ignition temperature of $400^{\circ}$ combust in situ in Xinjiang and are effected by coal fires. In former Yugoslavia lignites burn in an open pit in the Kosovo Province ignited by spontaneous combustion. Krietsch [3] could prove that the content of sulphur is not a main factor of spontaneous combustion. Coal with high contents of sulphur and nearly sulphur-free coals are ignited by spontaneous combustion. The same study verifies that the ratio of the surface to the volume of the coal is one of the main key factors for spontaneous combustion. Due to this fact the most endangered coal to combust is coal powder without reference to the chemical composition of the coal.

A coal fire can be observed at the Earth's surface only in its initial phase, when it is just starting, or in its final phase, when the fire has burnt through to the surface from underlying mine workings. Naturally, a great number of coal fires are in between these two stages and are not visible at the Earth's surface. In such cases solely circumstantial evidence indicates the approximate location of a fire to the fire fighter, such as: temperature anomalies, condensed hydrocarbons, sulphuric efflorescence, glauber salt or, in the simplest case, steam or smoke. These indicators, however, do not suggest how far away a coal fire is, as the pathways through the bedrock via fissures or mine workings affect their appearance.

\section{Greenhouse Gases}

Coal fires produce all kind of greenhouse gases: $\mathrm{CO}, \mathrm{CO}_{2}, \mathrm{CH}_{4}$, $\mathrm{NO}_{\mathrm{X}} \mathrm{SO}_{\mathrm{x}}$ etc. Due to the incomplete combustion under the surface, coal fires in the underground produce more of these gases, then a complete combustion of coal at the surface. A complete combustion of $1000 \mathrm{~kg}$ of coal with $750 \mathrm{~kg}$ of C leads to 2.7 tons of $\mathrm{CO}_{2}$. An incomplete combustion of $1000 \mathrm{~kg}$ of coal with $750 \mathrm{~kg}$ of $\mathrm{C}$ leads to 1.3 tons of $\mathrm{CO}_{2}$, and 0.8 tons of $\mathrm{CH}_{4}$. Methane interferes with the atmosphere 21 to 23 times more than $\mathrm{CO}_{2}$ thus having a much greater greenhouse effect. As result of an incomplete combustion of $1000 \mathrm{~kg}$ coal with $750 \mathrm{~kg} \mathrm{C} 5.1$ tons of $\mathrm{CO}_{2 \text { equivalent }}$ are caused from a coal fire (Figure 2).

Van Genderen, et al. reported for the year 199720 million tons of coal waste in China by coal fires. 20 Mill.tons of coal means 100 Mill.tons of $\mathrm{CO}_{2}$ only in China. For India actual or historic data are not available. There was in last years a calculation from the National Geographic's Magazine Indian coal fires produce 
yearly as much $\mathrm{CO}_{2}$ as 50 Million cars, but an actual calculation for India does not exist. Worldwide calculations are also not available- the problem is not in the focus of United Nations.

The Clean Development Mechanism (CDM) as part of the Kyoto Protocol opens the possibility to generate Certified Emission Reductions (CER) by means of the extinction of coal fires. The aim of

The Kyoto Protocol is to reduce the worldwide output of greenhouse gases. The Clean Development Mechanism is an instrument developed to provide an incentive to invest in projects that promote sustainable development and reduce the emission of greenhouse gases (Figure 3). Successful fire fighting can create earnings by certificates, sufficient to compensate for the expenses [4]. The worldwide emissions of greenhouse gases caused by coal fires are enormous. Most countries affected by coal fires are the newly industrializing counties and fast developing nations in Asia. If the firefighting institutions of these countries receive an instrument to fund their efforts by trading greenhouse gases emission rights, the results and successes of such efforts could be maximized. To determinate a baseline of any greenhouse gases emissions the knowledge of the future regime of the combustion processes is most essential. Due to the discussed features of coal fires a baseline determination under the actual legal conditions of guidelines is impossible, even with a lot of goodwill. The conditions to generate baselines for greenhouse emissions were framed for industrial processes. In industrial operations the combustion processes are controllable and measurable. The United Nations Framework Convention on Climate Change (UNFCCC) prescribes the following formula to calculate the $\mathrm{CO}_{2}$ emissions from fossil fuel combustions $\left(\mathrm{PEFF}_{\mathrm{y}}\right)$ :

$\mathrm{PEFF}_{\mathrm{y}}=\Sigma \mathrm{F}_{\mathrm{iy}} * \mathrm{COEF}_{\mathrm{i}}$

$\mathrm{PEFF}_{\mathrm{y}}=$ the project emissions from combustion of fossil fuels in tons of $\mathrm{CO}_{2}$

$\Sigma \mathrm{F}_{\mathrm{iy}}=$ is the fuel consumption of fuel type i furing the year $\mathbf{y}$ $\mathrm{COEF}_{\mathrm{i}}=$ the $\mathrm{CO}_{2}$ emission factor of the fuel type $\mathrm{i}$

$\begin{array}{lr}\text { UNFCCCICCNUCC } \\ \text { CDM - Meth Panel } & \begin{array}{c}\text { AM00XX/Version } 01 \\ \text { Sectoral Scopes: XX } \\ 16 \text { November } 2004\end{array} \\ \text { (page 3) } & \text { DRAFT }\end{array}$

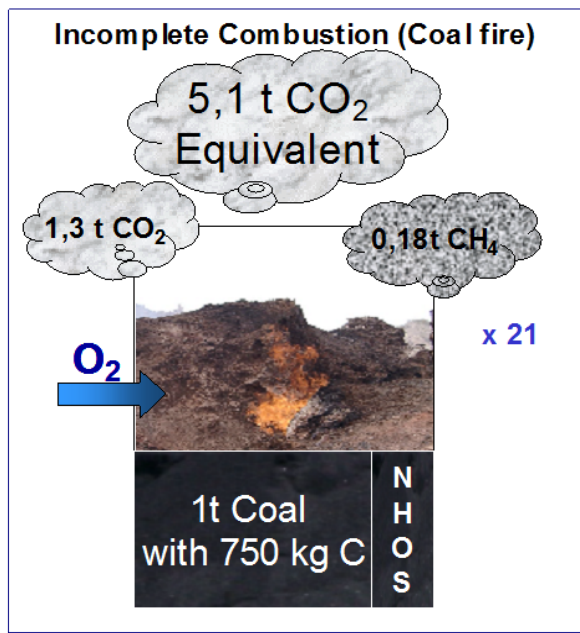

Figure 2. Greenhouse Gases from complete and incomplete combustion (Goerlich, 2004).

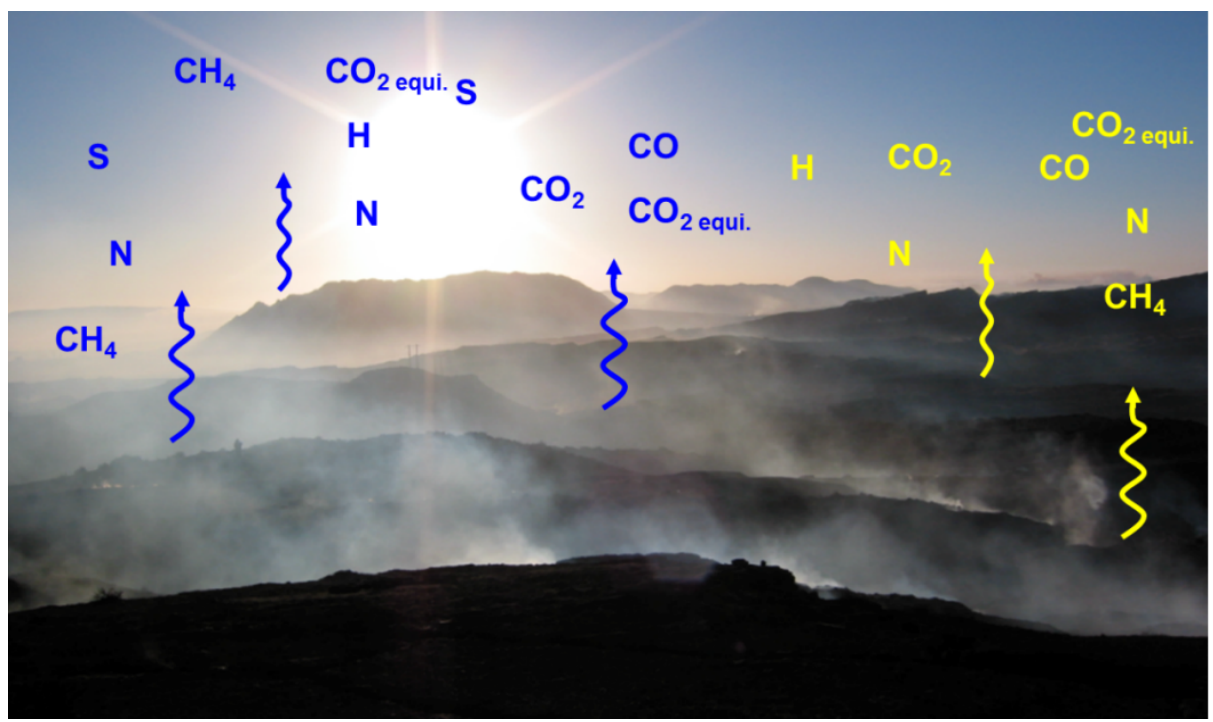

Figure 3. Burning coal field in NW-China. 
Burning 200 tons of coal in a technical obsolete power plant will produce $\mathrm{X}$ tons of greenhouse gases. Streamlining the production and modernizing the power plant, will produce $\mathrm{X}$ minus $\mathrm{Y}$ tons of greenhouse gases. This effect is measurable and it is possible to predict the annual future decrease of greenhouse gases. Such predictable annual decreases of greenhouse gases are not possible to determine for coal fires with unknown future regimes. A coal fire is a chaotic system. Three dozen parameters influence the genesis, the durability, the regime and the intensity of such a fire. The regime during the coal fires durability is not possible to predict. Coal fires do not burn consistently. Burning processes and the intensity of combusting is influenced by the local and the regional weather conditions. Like it is not possible to predict the local weather for the January in 5 years, it is also not possible to predict the amount of coal which will be combusted in the January in 5 years. We all know that predictions are a complicated business, especially when you try to predict the future. Nobody will count on a local weather forecast for Jan 1st 2023. Neither will it be possible to predict how much the amount of self-ignited coal will be in 5 years. Perhaps the DMT has since erased all the fires?

Here the responsible institutions which evaluate and refereed the baseline determinations and franchised the allocations of greenhouse gases emission rights are asked to find a legal solution to handle emissions caused by coal fires.

\section{References}

1. Van Genderen JL, Haiyan G. Environmental monitoring of spontaneous combustion in the North China coalfields.Final Report to European Commision under Contract CI1*CT93-0008 (DG-HSMV), European Commision. 1997.

2. Gielisch H. Detecting concealed coal fires. In: Stacher G (editors): Geology of Coal Fires: Case Studies from Around the world. 199-210, Rev. in Engineering Geology XVIII, Geol. Soc. America, Boulder Colorado. 2008.

3. Krietsch A, Schmidt M, Suhendra Helmis M (2010): Laboratory Investigations on the Ignition and Burning Process of Coal: fire Characteristics and Gas Emissions. In: Drebenstedt C (editor): Latest Developments in Coal fire Research- Bridging the science, economics, and Politics of a Global disaster; Proceedings of "ICCFR2; Second International Conference on Coal Fire Research, p. 147152, Freiberg.

4. Bandelow FK, Gielisch H, Schulz J. CER- Trading as a possibility to fund the fighting of uncontrolled coal fires in China. ERSEC Ecological Book Series- 4 on Coal Fire Research, UNESCO, Beijing. 2008: 585-593.

\section{*Correspondence to:}

Hartwig Gielisch

DMT GmbH \& Co. KG

Geo Engineering \& Exploration

Am Technologiepark 1

45307 Essen

Germany

Tel: + 49201 172-1888

E-mail: Hartwig.Gielisch@dmt-group.com 